\title{
A RACIONALIDADE LIMITADA DAS DECISÕES DE INVESTIMENTO EM TECNOLOGIA DA INFORMAÇÃO UMTEDRAIONAUTYININFORMAIONTECHNOOYIMESIMENTDEGSIONS
}

\section{RESUMO}

A literatura sustenta que a tecnologia da informação (TI), quando adequadamente combinada com outros recursos internos, pode desenvolver características difíceis de ser imitadas pela concorrência. Entretanto, nem sempre isso é fácil de conseguir. Alguns casos emblemáticos de insucesso que envolve empresas proficientes nas melhores técnicas de aplicação da TI nos negócios estimulam uma análise mais atenta sobre os mecanismos da geração de valor para o negócio. N este artigo, revelamos os resultados de um estudo de casos múltiplos, incorporados em organizações proficientes, para a compreensão do valor da utilização da TI e discutimos proposições sobre o porquê de algumas organizações apresentarem resultados superiores a outras. N ossa análise indica que a efetividade alcançada pelo uso da TI está de fato relacionada com a habilidade dos gestores de identificarem ineficiências econômicas prévias na dinâmica dos negócios e mitigá-las pela aplicação da TI, o que não é conseguido com as técnicas de análise de investimento atualmente empregadas.

\section{Otávio Próspero Sanchez}

Professor da Escola de Administração de Empresas de São Paulo, Fundação Getulio Vargas - SP, Brasil otavio.sanchez@fgv.br

\author{
Alberto Luiz Albertin \\ Professor da Escola de Administração de Empresas de São Paulo, Fundação Getulio Vargas - SP, Brasil \\ albertin@fgv.br
}

Recebido em 26.08.2008. Aprovado em 14.10.2008.

Avaliado pelo sistema double blind review

Editor Científico: Francisco Aranha

\begin{abstract}
Literature upholds that Information Technology (IT), when adequately combined with other in-house resources, may result in characteristics that are hard for the competition to copy. However, this is not so easy to achieve. Some emblematic unsuccessful cases involving companies with extensive experience in applying the best techniques in implementing business IT solutions have encouraged us to take a deeper look regarding the mechanisms used to generate value for businesses. In this article, we reveal the results of a variety of case studies, where competent organizations adopted IT solutions, to understand the value said adoption represents and discuss some hypothesis why some organizations had better results than others. O ur analysis indicates that effectiveness achieved through the use of IT is indeed related to managements' ability to identify previous economic inefficiencies in the business model and mitigate such inefficiencies by implementing IT solutions, which is not achievable through investment analysis techniques currently employed.
\end{abstract}

PALAVRAS-CHAVE Efetividade de investimentos em TI, decisão de investimentos em TI, valor da TI, racionalidade limitada, MATIF. KEMORDS IT investment effectiveness, IT investment decisions, IT value-added, limited rationality, MATIF. 


\section{INTRODUÇÃO}

Alcançar efetividade em investimentos em Tecnologia da Informação ( $\mathrm{TI}$ ) tem-se tornado uma das primordiais preocupações para as organizações, à medida que a competitividade no ambiente denegócios aumenta e gera pressões sobre as empresas (KOHLI e DEVARAJ, 2003). Em vista disso, a literatura tem enfatizado as maneiras pelas quais a TI pode melhorar o posicionamento estratégico das organizações pela sua adequada combinação com outros recursos internos, como habilidades dos colaboradores, processos al inhados e estrutura organizacional adequada (SCHNIEDERJANS, HAMAKER E SCHNIEDERJANS, 2004; WADE e HULLAND, 2004).

Vários estudos têm indicado que, internacionalmente, o montante de investimentos em TI tem alcançado cerca de $50 \%$ do total de investimentos feitos pelas empresas. No Brasil, as cifras têm atingido valores significativos e comparáveis percentualmente a países mais desenvolvidos (MEIRELLES, 2006). A proporção de investimentos em relação à receita tem aumentado, à medida que a complexidade do ambiente de negócios está aumentando (MELVILLE, KRAEMER eGURBAXANI, 2004), o que tem priorizado 0 assunto da decisão de investimentos em $\mathrm{TI}$ na agenda dos executivos.

Embora o montanteinvestido em TI pelas organizações venha aumentando nos últimos anos, al gumas pesquisas têm reconhecido a dificuldade de se objetivar a análise desse tipo de investimentos, dado que os benefícios para as organizações apresentam aspectos de intangibilidade usualmente associados à atividade de negócios, competição de mercado, presença geográfica e satisfação de cliente, ente outras (MELVILLE, KRAEM ER eGURBAXANI, 2004). As decisões de investimento em TI têm sido frequentemente vistas como arriscadas e complexas, tornando-se um assunto interdisciplinar e suportado por uma miríade de métodos financeiros, não-financei ros e mistos, como ROI, Payback, EVA, BSC, custo/benefício, custos de transação, análise de gaps, entre outros (ALBERTIN, 2001).

Em uma escalada crescente de complexidade, as organizações tendem a lidar com um grande número de projetos simultâneos, em uma situação em que os custos tendem a ser mais facilmente identificados, mas os benefícios nem sempre o são. Assim, o valor percebido do benefício é um elemento fundamental para a decisão de optar por determinado investimento em $\mathrm{TI}$ e envolve lidar com aspectos de intangibilidade e complexidade normalmente associados à consecução dos negócios. Em razão disso, visando a atingir maior efetividade nas decisões de investimento em TI, observam-se duas vertentes de ação nas organizações: (a) os executivos de negócios tendem a ser mais envolvidos nas decisões sobre TI, pois têm melhores condições de perceber a parcela intangível do benefício e (b) os executivos de TI têm sido demandados em direção a um maior envolvimento nas questões de negócio, em um relativo maior afastamento das decisões puramente técnicas (BASSELLIER, BENBASAT e REICH, 2003).

Considera-se que o compartilhamento de conhecimentos entre os dois perfis de executivos é um importante habilitador do alinhamento entre os objetivos de negócios e de TI (REICH e BEN BASAT, 2000). Entretanto, a percepção do valor criado pela aplicação de TI nos negócios pelos executivos élimitada devido à escassez de habilidades pessoais específicas requeri das para uma anál ise apropriada das questões envolvidas em dois domínios tão diversos (SIM ON , 1978), estratégia de negócios e tecnologia, domínios que requerem conhecimentos e racionalidades diversos (TALLON, KRAEMER e GURBAXANI, 2000; BASSELLIER, BENBASAT e REICH, 2003). Entretanto, ainda que um extenso conjunto de teorias procure explicitar os mecanismos de melhor gestão de $\mathrm{TI}$, existe certa inconsistência entre os seus resultados para o negócio obtidos por diferentes organizações na aplicação de sistemas de informações, por vezes surpreen dendo os gestores (SANTHANAM e HARTON 0, 2003).

As teorias de estratégia que focam a ação otimizadora do gestor sobre os recursos indicam a combinação apropriada de recursos, dentre eles a TI, como fonte de valor para os negócios, mas não explicam como essa combinação deve ser feita. Por outro lado, as teorias de gestão de TI ocupam-se de como lidar com a TI, mas o fazem em duas vertentes básicas: uma prescritiva sobre o que seria considerado como as melhores práticas e técnicas de concepção e aplicação da tecnologia nas organizações, mantendo-se mais no campo da gestão técnica, e outra em que se preconiza o alinhamento da chamada estratégia de TI com a estratégia de negócios, supondo que esta se desenvolva com vistas à geração de valor para o negócio e aquela lide com os aspectos tecnológicos de sua realização. N enhuma delas, entretanto, mostra efetivamente onde e como usar a TI para gerar valor para os negócios, dentre as inúmeras possibilidades estratégicas e tecnológicas que se apresentam. Assim, as organizações desenvolvem estratégias de negócios, estratégias de gestão de TI e aplicam técnicas de gestão desses recursos, mas não identificam exatamente quais investimentos têm o potencial de gerar valor de fato.

A proposta deste artigo é apresentar um novo desenvolvimento teórico que preenche a lacuna existente entre as teorias de estratégia e de gestão de TI, contribuindo 
para sua capacidade explicativa da geração de valor para as organizações. A concepção desse quadro de referência é amparada na Ex-ante Economic Inefficiency Hypothesis (EEIH), uma formulação conceitual embasada no conjunto de teorias microeconômicas neoclássicas que fornece a explicação para inúmeros casos de desequilíbrios informacionais encontrados no relacionamento entre agentes econômicos que, por sua vez, levam a alocações subótimas de recursos - 0 aproveitamento inadequado desses recursos -, o que determina resultados para os agentes abaixo do que seria possível se tais situações de ineficiência econômica não existissem (MILGROM e ROBERTS, 1992; HUNT, 1997; VARIAN, 1999). Efetuamos o desenvolvimento teórico que adapta a EEIH à circunstância da utilização de TI para definir que as ineficiências econômicas prévias à aplicação da TI são antecedentes da efetividade da aplicação de TI que as resolve. Posto de outra forma, se não houver ineficiência econômica a ser resolvida, o uso da TI é inócuo, não gera valor, configurando um investimento ineficiente no sentido de geração de valor. Para explicar como a EEIH pode influir decisivamente na geração de valor pela aplicação da TI, o referencial teórico desta pesquisa consiste dos principais conceitos da economia neoclássica (WEINTRAUB, 2002), ou seja, a idéia do indivíduo e da firma como agentes maximizadores de, respectivamente, utilidade (conforme proposto inicialmente por John Stuart M ill) elucro (neste artigo, substituímos o conceito de lucro pelo de geração de valor). Assim, utilizamos a teoria dos custos de transação (TCE) proposta por Coase (WILLIAMSON, 1979; WILLIAM SON, 1986), a economia do desenho organizacional (MILGROM eROBERTS, 1992), e outras, predominantemente, orientadas para os variados aspectos econômicos do uso da informação (VARIAN, 1999; BENAROCH, 2001; ORLIKOWSKI, 2002; CLEMONS e HITT, 2004; WADE e HULLAND, 2004; MAYER E SALOMON, 2006).

Adicionalmente ao desenvolvimento teórico, apresentamos um estudo empírico que testa a aplicação do quadro conceitual na explicação de casos de inconsistências observadas em situações em que as melhores práticas tivessem sido empregadas, mas ainda assim não se configurasse a efetividade dos investimentos, e conduzimos um estudo de caso no setor bancário do Brasil, por ser este considerado maduro na aplicação de TI, com um histórico de vários anos de inovação e competitividade em nível mundial. Para tanto, desenvolvemos o MATIF Modelo de Análise do uso de Tecnologia da Informação no nível da Firma, que é o construto derivado da aplicação da EEIH .
Assim, foram selecionadas situações relevantes de desequilíbrio entre expectativa e realização, ainda que as organizações tenham aplicado todas as mel hores técnicas para uma tomada de decisão e para a gestão do projeto em um setor intensivo na aplicação de TI (grande número de projetos, por um longo período) tanto na condição de empresas líderes em um setor competitivo de informação-intensivo tanto em seu setor (proxy da habilidade na compreensão do val or que a TI tem para os negócios), quanto de empresas líderes na utilização da TI (proxy da habilidade na gestão de TI e projetos).

Este trabalho está organizado como se segue. Inicial mente revisamos a literatura rel evante sobre a criação de valor no nível da firma e apresentamos detal hes do MATIF. A seguir, apresentamos as razões que levaram à escolha do método empírico e das técnicas utilizadas. $\mathrm{Na}$ seção seguinte, apresentamos uma visão geral dos casos incorporados. Em seguida, analisamos e interpretamos os dados, usando o conceito da ineficiência econômica e da maximização do investimento em TI para apresentar o entendimento sobre o papel da EEIH na criação de valor no nível da firma. Finalmente, discutimos as contribuições do artigo para a prática gerencial e as implicações para pesquisas futuras.

\section{CRIAÇÃO DE VALOR NO NÍVEL DA FIRMA}

A seguir, descreveremos os principais el ementos teóricos necessários para o suporte deste trabalho. Definiremos o conceito de modelo de firma e apresentaremos argumentos do porquê de se analisar a firma pela lógica do EEIH. Adicionalmente, expomos dois conceitos fundamentais para a parte empírica deste trabal ho, a percepção de val or pelos executivos e a visão de sucesso e fracasso de projetos de investimento em TI.

\section{Modelo da firma}

Da teoria econômica, definimos a gestão da firma como sendo o conjunto de atos deliberados que visa ao intento estratégico de criação de valor. Esses atos envolvem o relacionamento com outros agentes econômicos (VARIAN, 1999) ea combinação de recursos e capacidades internas e externas à firma (PENROSE, 1997; M AYER eSALOM ON, 2006). As decisões sobre a correta combinação desses recursos e capacidades permitem à firma gerar e capturar parte desse val or econômico gerado nos relacionamentos entre agentes. A firma terá sido efetiva em suas escolhas se 0 valor econômico gerado por esse processo for superior ao custo de oportunidade de outras alternativas 
também viáveis, considerando-se determinado nível de risco (MILGROM e ROBERTS, 1992; BODIE, KANE e MARCUS, 1999).

0 relacionamento fundamental da firma, como um agente econômico no mercado, ocorre com clientes, sendo que 0 atributo desse relacionamento é a entrega de utilidade. Assim, clientes aceitam manter relações de negócio com a firma, dependendo da percepção de recebimento de uma contrapartida em utilidade. Para essa adequada entrega de utilidade, as firmas desenvolvem meios de produção que consistem em recursos e capacidades internos e, eventualmente, externos, se o custo de integração interna desses recursos for superior (WILLIAMSON, 1986). Freqüentemente, a capacidade de criar val or e capturá-lo depende da estratégia seguida pela firma para uma apropriada combinação que envolve a complementaridade entre os recursos e capacidades internos e externos, descrita na literatura de Resource-Based View - RBV (PEN ROSE, 1997; WADE eHULLAN D, 2004). Diante disso, a capacidade de aplicar adequadamente o recurso da TI tem-se tornado fundamental para a criação de valor pelas firmas, em especial nas chamadas economias da informação (TEECE, 1992), em que a parcela informacional contribui significativamente para o valor dos bens e serviços (VARIAN e SHAPIRO, 1999; EVAN S e WURSTER, 2000).
Como nem todas as capacidades e recursos estão disponíveis internamente, a viabilização da criação de valor depende do estabelecimento de relacionamento de cooperação com parceiros e fornecedores, que passam a contribuir com insumos e partes do processo, permitindo à firma utilizar mais adequadamente seus recursos e capacidades internas especializadas (PRAHALAD e HAMEL, 1990; CLEM ONS e ROW, 1992), visando a beneficiar-se de economias de escala e escopo internas ou externas (CHANDLER, 1997).

Ao decidir investir em determinada atividade, a firma compara os riscos e os retornos de seu portfólio de produtos e serviços, assim como da internalização de recursos e capacidades, comparando-os com outras alternativas viáveis (BODIE, KANE e MARCUS, 1999). Essa avaliação requer essencialmente informação e permanente monitorização do ambiente de negócios (CLEMONS e HITT, 2004).

Sumariamente, o modelo de efetividade da gestão da firma inclui a adequação dos relacionamentos externos com clientes e parceiros/fornecedores, bem como a complementaridade do conjunto interno e externo de Recursos eC apacidades, visando a gerar Valor Econômico superior, a um risco consistente com alternativas viáveis, conforme ilustrado na Figura 1.

Figura 1 - Modelo de criação de valor da firma

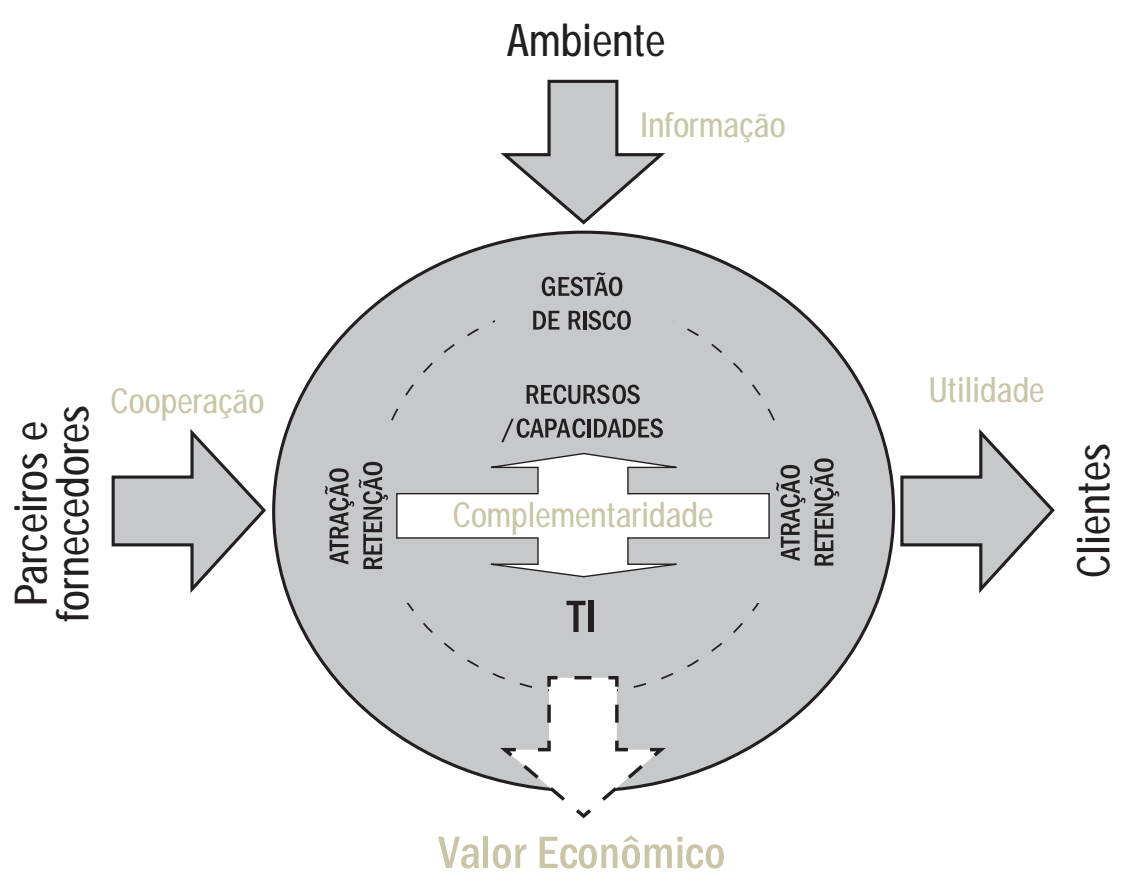




\section{Ex-ante Economic Inefficiency Hypothesis (EEIH)}

0 argumento de que mercados economicamente eficientes liberam valor para os agentes é clássico na literatura econômica (WILLIAMSON, 1975; PINDYCK e RUBINFELD, 2006). No âmbito das rel ações entre agentes, uma situação de ineficiência decorre de imperfeições econômicas quelevam a resultados subótimos na liberação de val or. Isso significa que, uma vez resolvidas essas ineficiências, a solução ex-post émel hor que a ex-ante, levando os agentes econômicos a se beneficiarem dessa situação (VARIAN, 1999).

Levando-seem consideração que os negócios consistem em relacionamentos entre agentes que podem ser eficientes ou não, e sendo esses relacionamentos essencial mente informacionais, deduz-se que a ocorrência de ineficiências econômicas pode ter origem informacional. Esse argumento tem sido economicamente elaborado por vários autores no campo de pesquisas pertencente à intersecção entre economia e sistemas de informação (SHAPIRO e KATZ, 1986; TEECE, 1992; BRYNJOLFSSON, 1993; CASSO N, 1994; BARUA, KRIEBEL E MUKHOPADHYAY, 1995; BAILEY E BAKOS, 1997; VARIAN E SHAPIRO, 1999; PORTER, 2001; BRYNJOLFSSON e HITT, 2003;
KOHLI e DEVARAJ, 2003; CLEMONS e HITT, 2004; MELVILLE, KRAEMER E GURBAXANI, 2004; MAYER e SALOMON, 2006).

O Quadro 1 apresenta um conjunto não exaustivo de referências na literatura desse campo, organizadas em função das cinco dimensões do modelo representado na Figura 1. Com base nesse referencial, definimos o construto a priori desta pesquisa (EISENHARDT, 1989), que representamos por meio do MATIF exposto na Figura 2.

Considerando que a aplicação da TI pode colaborar para a mitigação dos problemas de ineficiência informacional entre os agentes, a identificação prévia das circunstâncias de ineficiência econômica de base informacional pode orientar a tomada de decisão quanto à utilização de TI e, conseqüentemente, quanto à decisão de investimentos, à medida que a resolução dessa ineficiência prévia por meio da aplicação da TI gera val or econômico, proposição suportada conceitual mente pela EEIH.

\section{Decisão de investimento e percepção de valor}

A decisão de investimento em geral baseia-se na racio-

Quadro 1 - Dimensões, conceitos econômicos e referências na literatura

\begin{tabular}{|c|c|c|}
\hline $\begin{array}{l}\text { DIMENSÕES } \\
\text { DO MODELO }\end{array}$ & PRINCIPAIS CONCEITOS ECONÔMICOS & $\begin{array}{l}\text { REFERÊNCIAS NA } \\
\text { TEORIA ECONÔMICA }\end{array}$ \\
\hline $\begin{array}{l}\text { UTILIDADE } \\
\text { (Relação com Clientes) }\end{array}$ & $\begin{array}{l}\text { Custos de localização, substitui- } \\
\text { ção e transação, coordenação, pa- } \\
\text { dronização. reputação / garantias, } \\
\text { moral hazard, seleção adversa }\end{array}$ & $\begin{array}{l}\text { (WILLIAMSON, 1979; MILGROM e ROBERTS, 1992; BAILEY e } \\
\text { BAKOS, 1997; VENKATRAMAN e HENDERSON, 1998; VARIAN, } \\
\text { 1999; EVANS e WURSTER, 2000; PORTER, 2001; MELVILLE, } \\
\text { KRAEMER e GURBAXANI, 2004) }\end{array}$ \\
\hline $\begin{array}{l}\text { COOPERAÇÃO } \\
\text { (Relação com Parceiros } \\
\text { e Fornecedores) }\end{array}$ & $\begin{array}{l}\text { Co-especialização, volume e freqüência } \\
\text { de transação, reputação / garantias, } \\
\text { externalidades, concentração, coorde- } \\
\text { nação, complementaridades }\end{array}$ & $\begin{array}{l}\text { (SHAPIRO e KATZ, 1986; WILLIAMSON, 1986; MILGROM e } \\
\text { ROBERTS, 1992; TEECE, 1992; CASSON, 1994; WILLIAMSON, } \\
\text { 1996; CHANDLER, 1997; VENKATRAMAN e HENDERSON, } \\
\text { 1998; VARIAN e SHAPIRO, 1999; PORTER, 2001) }\end{array}$ \\
\hline $\begin{array}{l}\text { COMPLEMENTARIDADES } \\
\text { (Relação entre Recursos } \\
\text { e Capacidades) }\end{array}$ & $\begin{array}{l}\text { Complementaridades internas e exter- } \\
\text { nas, substituição técnica dos fatores, } \\
\text { custo de oportunidade }\end{array}$ & $\begin{array}{l}\text { (TEECE, 1987; CHANDLER, 1990; PRAHALAD e HAMEL, 1990; } \\
\text { TEECE, 1992; BARUA, KRIEBEL e MUKHOPADHYAY, 1995; } \\
\text { CHANDLER, 1997; PENROSE, 1997; POWELL e MICALLEF, } \\
\text { 1997; VARIAN, 1999; PORTER, 2001; BRYNJOLFSSON e HITT, } \\
\text { 2003; WADE e HULLAND, 2004) }\end{array}$ \\
\hline $\begin{array}{l}\text { RISCO } \\
\text { (Relação com o Ambiente) }\end{array}$ & $\begin{array}{l}\text { Assimetrias de informação, opções re- } \\
\text { ais, avanços tecnológicos, padronização, } \\
\text { externalidades de rede, lock-in }\end{array}$ & $\begin{array}{l}\text { (SIMON, 1978; TEECE, 1992; CASSON, 1994; WILLIAMSON, } \\
\text { 1996; VENKATRAMAN e HENDERSON, 1998; BENAROCH e } \\
\text { KAUFFMAN, 1999; BODIE, KANE e MARCUS, 1999; VARIAN, } \\
\text { 1999) }\end{array}$ \\
\hline VALOR ECONÔMICO & $\begin{array}{l}\text { Economias de escopo, economias de } \\
\text { escala, custos de transação, custos de } \\
\text { coordenação }\end{array}$ & $\begin{array}{l}\text { (BRYNJOLFSSON, 1993; BRYNJOLFSSON e HITT, 1996; } \\
\text { WILLIAMSON, 1996; HUNT, 1997; MELVILLE, KRAEMER e } \\
\text { GURBAXANI, 2004) }\end{array}$ \\
\hline
\end{tabular}


nalidade de que haverá valor econômico positivo gerado. Assim, avaliam-se os benefícios versus os custos, sendo que nem todos os benefícios podem ser expressos em termos financeiros, mas usualmente os custos o são. Benefícios não financeiros são conhecidos como benefícios intangíveis na literatura (GARDNER, 2000; SCHNIEDERJANS, HAMAKER E SCHNIEDERJANS, 2004), e sua avaliação depende da percepção de seu valor pelos decisores.

Dois tipos de percepções de valor de investimento são reconhecidos pela literatura: (a) valor potencial, que consiste no máximo valor que a aplicação de TI pode gerar, avaliado antes da implementação (ex-ante); e (b) valor realizado, derivado da implementação, ex-post (DAVERN e KAUFFMAN, 2000). Alcançar a realização do valor potencial, transformando-o em valor realizado, depende da suplantação das contingências durante a implementação, conforme ilustrado na região destacada da Figura 3. Entretanto, a percepção dos executivos é freqüentemente limitada (SIM ON, 1978) pela fal ta de habilidades específicas para avaliar a situação em dois domínios diferentes da firma: as questões de estratégia de negócios e de tecnologia (TALLON, KRAEMER e GURBAXANI, 2000; BASSELLIER, BENBASAT e REICH, 2003). A fal-

Figura 2 - Dimensões do construto MATIF

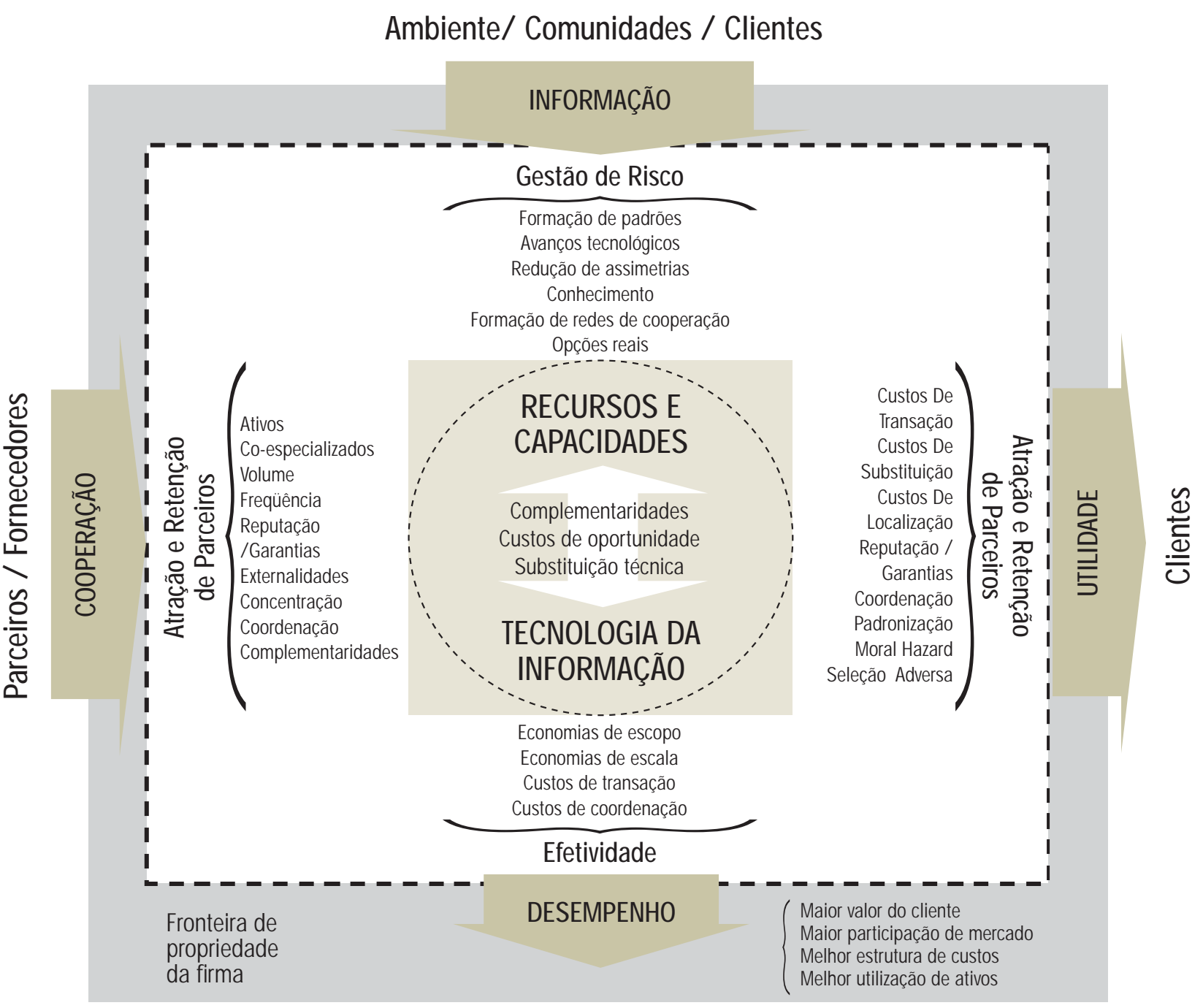

Stakeholders 
ta de compreensão das racionalidades desses diferentes campos de conhecimento pode representar enorme impacto quanto ao sucesso ou fracasso dos projetos de investimentos em TI. Essas fal has de compreensão podem levar a uma incompleta identificação do valor potencial, o que significa que, na verdade, os executivos estarão avaliando os projetos de investimento em TI pelo valor efetivamente percebido (valor percebido) e não pelo valor potencial, sendo que a eventual diferença entre um e outro é atribuída a barreiras de percepção dos executivos, conforme ilustração da Figura 3.

\section{Sucesso e fracasso em projetos de investimentos em TI}

Ao quadro de referência anteriormente descrito sobre percepção de valores (DAVERN e KAUFFMAN, 2000) incluímos o valor potencial que é um valor idealizado e representa um papel central neste artigo. Tomando-se como base a EEIH , situações em que houvesse ineficiência econômica prévia tenderiam a liberar valor econômico positivo quando aplicações de TI fossem feitas para resolver tais ineficiências. Por outro lado, na ausência de tais ineficiências, não haveria geração de valor econômico. Admitimos, por fim, que os executivos possam ter dificuldades em identificar tais circunstâncias de ineficiência, tendo em vista a extensão e a complexidade da multifacetada disciplina econômica, o que demandaria o domínio de conhecimentos diversos e racionalidades múltiplas, simultaneamente.

\section{METODOLOGIA}

Adotamos para esta pesquisa o estudo de caso por ser esta uma estratégia recomendável à medida que se queira construir teorias por meio do estudo da realidade em seu ambiente natural, compreendendo a complexidade dos inter-relacionamentos dos seus elementos (BENBASAT, GOLDSTEIN e MEAD, 1987; EISEN HARDT, 1989). Para isso, foram selecionados projetos de investimento em organizações considerados casos extremos de fracasso ou surpreendente sucesso, adotando-se a comparação rel ativa entre valor percebido e valor realizado para a identificação de projetos considerados como apresentando sucesso ou fracasso.

0 desenho da pesquisa foi concebido para analisar se o quadro referencial teórico proposto seria capaz de explicar as ocorrências extremas de grande sucesso ou de surpreendente fracasso em projetos de investimento em tecnologia da informação. N essa abordagem, foi importante isolar outras possíveis causas pelas quais um projeto não fosse bem-sucedido, ou ainda a organização, por insuficiência de conhecimento, domínio ou acesso às melhores técnicas de análise, pudesse ser incapaz de an-

Figura 3 - Etapas da percepção de valor em projetos de TI
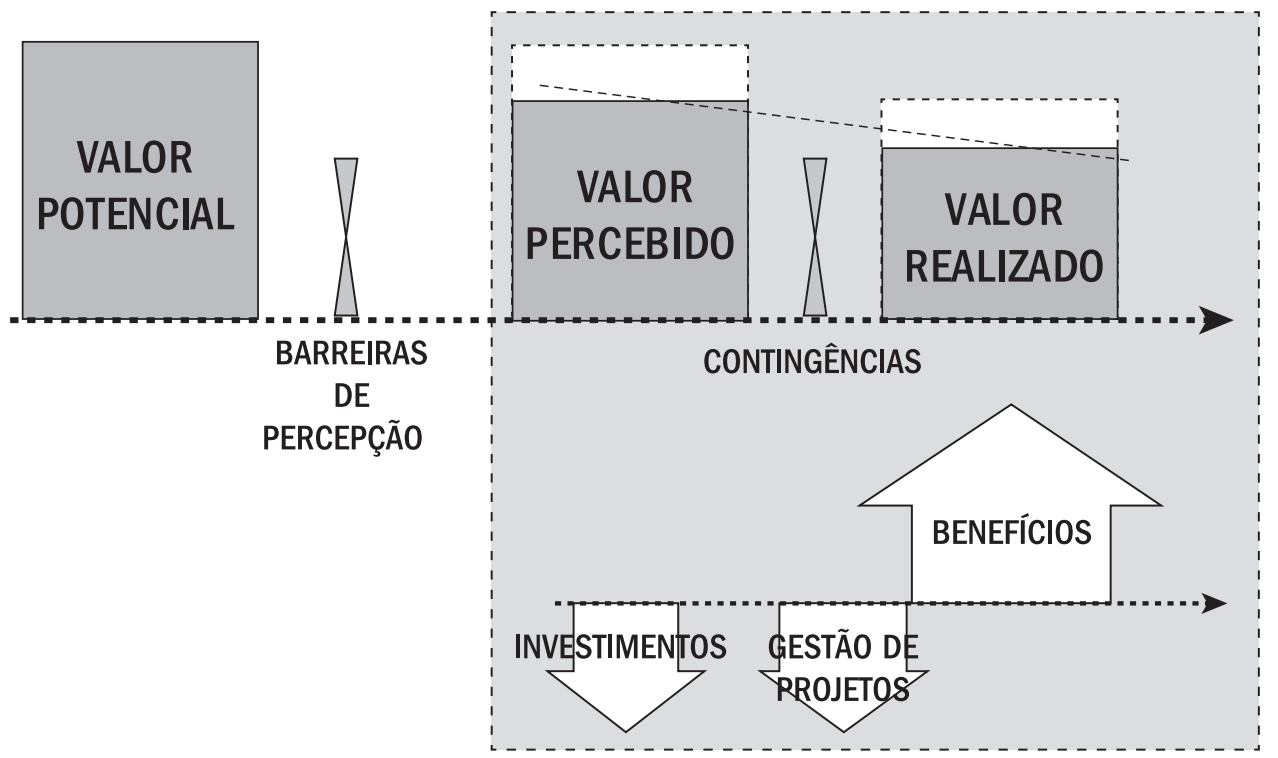
tecipar resultados previsíveis, considerando-se o estágio atual do conhecimento sobre esse assunto.

\section{Definição da amostra e descrição dos casos analisados}

Assim, tendo em vista o exposto, a amostra foi intencionalmente definida (EISENHARDT, 1989; YIN, 2002), dadas as seguintes condições iniciais:

(a) as organizações deveriam ser consideradas líderes no setor com uso de informação-intensivo. As organizações deveriam ser proficientes no uso de TI, assim como representativas em relação aos investimentos anuais, por um período mínimo de cinco anos. Essa condição foi considerada como proxy da competência no uso de TI e acesso às melhores práticas de gestão de TI e estratégia;

(b) deveriam ter executado grande quantidade de projetos de TI nos últimos cinco anos, a uma média de, pelo menos, 500 projetos por ano;

(c) deveriam apresentar uma dinâmica de negócios que envolvesse relacionamentos com parceiros de negócios e clientes tão hábeis na aplicação de TI quanto elas.

Uma vez satisfeitas essas condições, consideramos também necessário que as organizações apresentassem portes comparáveis de maneira que permitisse a replicação teórica entre os casos, objetivando confrontar os resultados com a teoria proposta pela EEIH (EISEN HARDT, 1989).

A lógica geral da pesquisa foi a de que os casos de insucesso ou sucesso não previstos pelos métodos disponíveis, portanto considerados extremos ou surpreendentes, deveriam ser passíveis de explicação pelo novo quadro de referência. Para a definição de sucesso, adotamos a comparação entre a percepção de valor gerado ao final da implementação do projeto (valor realizado) e a percepção de valor no momento da decisão de implementação (valor percebido). Conseguir uma amostra com empresas proficientes no uso da TI foi uma condição muito importante para a execução deste estudo, porque se objetivou isolar a interferência da fal ta de conhecimento e habilidade na aplicação das mel hores técnicas de implementação de projetos que pudessem mascarar eventuais diferenças entre os valores percebidos, sem relação, portanto, com as ineficiências econômicas prévias ao projeto.

0 setor que escolhemos para conduzir a pesquisa no Brasil foi o bancário, por ser considerado maduro na aplicação de TI, com um histórico de vários anos de inovação ecompetitividade em nível mundial. Por exemplo, o setor éconsiderado como aquel eque apresenta as melhores práticas e potencial para atrair as melhores habilidades e co- laboradores, tendo atingido a proporção de $11,1 \%$ de sua receita líquida em 2005 com gastos em TI (MEIRELLES, 2006). De acordo com a Federação dos Bancos do Brasil (FEBRABAN, 2006), o gasto total com TI no setor foi equivalente a US\$ 5.5 bilhões durante 0 ano de 2004. A maturidade na adoção da TI é revelada pela alta capilaridade apresentada pelas operações bancárias do país e pelo expressivo número de transações eletrônicas, conforme apresentado na Tabela 1

Para atender à condição de representatividade no setor, três dos principais bancos do Brasil foram selecionadas dentre os dez maiores bancos em ativos, conforme informado pelo Banco Central do Brasil (BACEN, 2006) na Tabela 2. Já o critério de escolha dos casos em relação à proficiência na utilização de TI baseou-se em periódicos da área de tecnologia. 0 procedimento usado consistiu em colher o nome das instituições em listas de profissionais ou implementações consideradas, em um processo de votação pela comunidade de tecnologia, os casos mais destacados ao longo de, pelo menos, mais de um ano, nas categorias tecnologia para serviços bancários, serviços financeiros e bancos. Para essa etapa, os periódicos considerados foram Info-Exame, IDG Now! e Relatório Bancário. Com base nessa consulta, foi elaborada uma lista combinada de instituições que atendessem a ambos os requisitos, o de uso de $\mathrm{TI}$ e o de representatividade no setor, o que resultou na lista de oito instituições.

Após a identificação dessa lista inicial, a pesquisa foi conduzida para identificar quais instituições permitiriam efetivo acesso, já que necessitaríamos obter informações detal hadas para uma pesquisa em profundidade, provavel mente necessitando obter informação de vários colaboradores, em várias áreas dos bancos, e acesso a documentos diversos, visando à triangulação dos dados (EISENHARDT, 1989; YIN, 2002).

\section{Casos selecionados}

Foram selecionadas três instituições financei ras de grande porte, e as entrevistas transcorreram entre março de 2005 e abril de 2006. Em razão das condições para participação impostas pelas instituições, a pesquisa apresenta apenas as informações consentidas pelas empresas. Foram escol hidos bancos privados, classificados dentre os sete maiores com perfis de clientes semelhantes e com operação em todo 0 território nacional, responsáveis conjuntamente por $22 \%$ do ativo do setor, $28 \%$ do patrimônio líquido total, mais de $20 \%$ do depósito a vista e mais de 4.000 agências no país, conforme dados de março de 2005 (BACEN, 2006).

No Quadro 2, apresentamos as características resumidas das três instituições escolhidas. 
Tabela 1 - Indústria bancária brasileira - crescimento da automação de processos

\begin{tabular}{|l|c|c|c|c|}
\hline \multicolumn{1}{|c|}{ (MILHÕES DE TRANSAÇÕES) } & 2002 & 2003 & 2004 & $2004 / 2005$ \\
\hline Automáticas externas (1) & 599 & 610 & 667 & $9,4 \%$ \\
\hline Automáticas internas (2) & 3.893 & 6.758 & 7.514 & $11,2 \%$ \\
\hline Auto-atendimento (3) & 6.094 & 7.585 & 9.891 & $30,4 \%$ \\
\hline Home e Office Banking P.J. (4) & 970 & 1.174 & 1.862 & $58,6 \%$ \\
\hline Internet Banking P.F. (5) & 1.139 & 1.457 & 2.045 & $40,4 \%$ \\
\hline POS - Ponto de Venda no Comércio (6) & 549 & 581 & 1.002 & $72,5 \%$ \\
\hline Transações de caixas de agências & 4.463 & 4.451 & 3.609 & $-8,9 \%$ \\
\hline № de cheques compensados & 2.397 & 2.246 & 2.107 & $-6,2 \%$ \\
\hline Call Center com intervenção atendente & 380 & 321 & 301 & $-6,3 \%$ \\
\hline Call Center (Unidade Resposta Audível) & 1.133 & 994 & 850 & $-4,5 \%$ \\
\hline Correspondentes Bancários (7) & - & 125 & 187 & $49,6 \%$ \\
\hline TOTAL & 21.617 & 26.302 & 30.035 & $14,2 \%$ \\
\hline
\end{tabular}

Fonte: Febraban, 2006, p. 4.

Notas: (1) Débitos automáticos, crédito de salário etc.
(2) Tarifas, taxas, IOF, CPMF etc.
(3) Saque, depósitos, consultas, emissão de cheques etc.
(4) Transferências de arquivos, consultas, pagamentos, investimentos etc.
(5) Consultas, transferências, pagamentos, investimentos, emprés imos etc.
(6) Pagamentos em lojas, supermercados, postos de gasolina etc.
(7) Estabelecimentos comerciais, correios, casas lotéricas etc.

Tabela 2 - Setor bancário - ranking pelo total de ativos, em 2005

\begin{tabular}{|c|c|c|c|c|c|c|}
\hline POS & INSTITUIÇÃOO & $\begin{array}{l}\text { ATIVO TOTAL } \\
\text { (US\$ } \$ 1.000)\end{array}$ & $\begin{array}{l}\text { PATRIMÔNIO } \\
\text { LÍQUIDO } \\
\text { (US\$1.000) }\end{array}$ & $\begin{array}{c}\text { RECEITA LÍQUI- } \\
\text { DA } \\
(\text { US } \$ 1.000)\end{array}$ & $\begin{array}{l}\text { TOTAL DE DEPÓ- } \\
\text { SITOS } \\
\text { (US\$ } 1.000)\end{array}$ & $\begin{array}{l}\text { NÚMERO DE } \\
\text { COLABORA- } \\
\text { DORES }\end{array}$ \\
\hline 1 & BB & 122.231 .522 & 7.429 .302 & 479.891 & 59.749 .499 & 103.965 \\
\hline 2 & CEF & 77.867 .402 & 3.471 .381 & 236.275 & 48.352 .257 & 104.435 \\
\hline 3 & BRADESCO & 77.015 .512 & 8.231 .370 & 599.815 & 35.554 .496 & 67.531 \\
\hline 4 & ITAÚ & 69.741 .843 & 8.343 .191 & 644.900 & 22.005 .894 & 47.918 \\
\hline 5 & UNIBANCO & 37.528 .398 & 4.283 .472 & 206.449 & 17.845 .824 & 23.282 \\
\hline 6 & SANTANDER BANESPA & 35.785 .166 & 4.123 .618 & 151.233 & 11.751 .657 & 21.380 \\
\hline 7 & ABN AMRO & 32.380 .627 & 4.543 .578 & 105.040 & 16.749 .746 & 28.297 \\
\hline 8 & $\mathrm{HSBC}$ & 20.837 .363 & 1.400 .672 & 72.555 & 12.893 .253 & 25.942 \\
\hline 9 & SAFRA & 19.177 .576 & 1.841 .389 & 69.416 & 4.782 .880 & 4.786 \\
\hline 10 & NOSSA CAIXA & 15.427 .446 & 1.115 .984 & 44.225 & 10.932 .850 & 14.316 \\
\hline
\end{tabular}

Fonte: Bacen, 2006.

Nota: Extrato da planilha de ranking de bancos disponível no site da Instituição. 
Depois de identificados os casos, o pesquisador identificou contatos que pudessem atuar como facilitadores da identificação do processo de decisão, visto que mapear a percepção de valor anterior à execução de projetos de investimento foi um importante requisito para a análise da efetividade do investimento. Em seguida, foram desenvolvidos questionários estruturados baseados na estrutura teórica do MATIF. Uma amostra desse questionário é mostrada no Quadro 3. Esses questionários foram encaminhados para os contatos iniciais junto aos casos pesquisados. Um alto nível de detalhe dos quesitos perguntados foi intencionalmente definido para que pudessem ser identificados na estrutura os informantes relevantes, considerados dessa forma aquel es que pudessem dispor de detal hes, documentos e histórico suficientes para caracterizar detal hadamente o que ocorreu desdea proposição do projeto de investimento até sua efetiva conclusão. Os informantes rel evantes apresentaram-se úteis por contribuir com informações que tendiam a ser mais objetivas e menos influenciadas pelos aspectos políticos da organização. A pós a identificação dos informantes relevantes, a segunda fase de coleta de dados propriamente dita foi real izada por meio de entrevistas semi-estruturadas conduzidas com base em um protocolo fundamentado no questionário previamente enviado. 0 protocolo do estudo de caso foi previamente avaliado por dois especialistas em anál ise de investimentos de tecnologia da informação com o objetivo de validá-los quanto à sua capacidade de cobertura relativa aos aspectos envolvidos no referencial teórico.

Uma vez identificada a estrutura de decisão de cada organização, cada equipe formada pelo conjunto de informantes rel evantes em cada caso pesquisado e pel o pesquisador decidiu quais projetos seriam avaliados, tendo como requisito inicial que consistissem em projetos que tivessem apresentado resultados surpreendentemente bons ou ruins, ressaltando o especial interesse na identificação de casos extremos (EISEN HARDT, 1989; YIN, 2002), em que cada val or realizado fosse identificado pelos

Quadro 2 - Caracterização dos casos

\begin{tabular}{|c|c|}
\hline & BANCO A \\
\hline Capital & $\begin{array}{l}\text { multinacional presente em } 70 \\
\text { países }\end{array}$ \\
\hline Patrimônio & US\$ 6 bilhões \\
\hline Ativos & US\$ 30 bilhões \\
\hline Número de clientes & 12 milhões \\
\hline $\begin{array}{l}\text { Número de contas } \\
\text { ativas }\end{array}$ & $\begin{array}{l}5,9 \text { milhões de contas correntes } \\
\text { e poupanças }\end{array}$ \\
\hline $\begin{array}{l}\text { Número de } \\
\text { colaboradores }\end{array}$ & 28.000 \\
\hline $\begin{array}{l}\text { Número de transações } \\
\text { por mês }\end{array}$ & 150 milhões \\
\hline Rede de captação & $\begin{array}{l}6.000 \text { pontos de acesso, } 1900 \\
\text { agências, } 600 \text { ATMs }\end{array}$ \\
\hline Observações & $\begin{array}{l}\text { Enfase no profissionalismo da } \\
\text { equipe; formação em referên- } \\
\text { cias internacionais de escolas } \\
\text { de negócios e tecnologia; fun- } \\
\text { damental a migração do foco da } \\
\text { equipe de } T \text { de perfil puramente } \\
\text { técnico para o perfil envolvido } \\
\text { em negócios }\end{array}$ \\
\hline
\end{tabular}

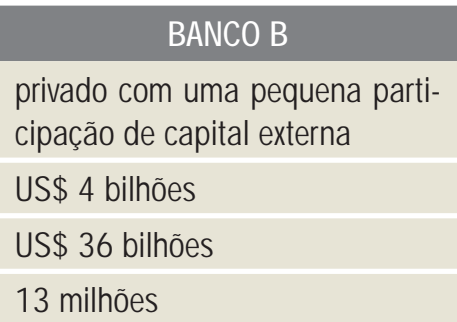

13 milhões de contas correntes e poupanças

\subsection{0}

100 milhões

17.000 pontos de venda, 900 agências, 350 agências em empresas parceiras, $2.700 \mathrm{ATMS}$

A estrutura organizacional é altamente profissionalizada; pessoal de TI faz a ponte entre as demandas das áreas de negócio, especialmente no que se refere às análises de investimento; 500 projetos de $T 1$ todos os anos

\section{BANCO C}

Top-3 dentre os maiores bancos privados

US\$ 8 bilhões

US $\$ 70$ bilhões

20 milhões

35 milhões de contas correntes e poupanças.

48.000

280 milhões; 400 milhões pela Internet

20.000 pontos de acesso; 22.000 ATMS

Reconhecido como formador de mão-de-obra e pela alta capacitação tecnológica de sua equipe; formação em referências internacionais de escolas de negócios e tecnologia

Fonte: Dados sobre capital, patrimônio e ativos. Bacen, 2006 Dados sobre captação, transações e rede. Febraban, 2006. 
entrevistados, em consenso, como sendo especialmente contrastante como valor percebido no momento da tomada da decisão do investimento. 0 fluxo detal hado das etapas da pesquisa é indicado na Figura 4.

\section{Seleção de projetos}

N este estudo, procuramos escolher os projetos com base, essencialmente, nas características que identificam, nas Organizações, quais investimentos em TI foram bem-

Quadro 3 - Trecho exemplar do questionário inicial

\begin{tabular}{|c|c|}
\hline & PERGUNTAS \\
\hline & 0 ao Projeto 1 \\
\hline 18 & $\begin{array}{l}\text { É um projeto de infra-estrutura - serve a várias aplica- } \\
\text { ções de negócios ou é um projeto de negócios }\end{array}$ \\
\hline 19 & $\begin{array}{l}\text { É um projeto com resultados localizados ou com re- } \\
\text { sultados distribuídos pela Organização }\end{array}$ \\
\hline 20 & $\begin{array}{l}0 \text { projeto é considerado bem sucedido ou mal sucedi- } \\
\text { do em relação à entrega de valor para o negócio }\end{array}$ \\
\hline
\end{tabular}

A nossa percepção ANTES de executarmos o projeto, era de que, com ele:

Reduziram as dificuldades ou custos que nossos

21 clientes enfrentam ao se relacionarem com nossa empresa

Aumentariam os atrativos para o cliente, evitando a

22 substituição de nosso produto ou serviço por outro da concorrência

Facilitaria com que 0 cliente identificasse 0 produto

23 ou serviço que melhor se adaptasse as necessidades dele

Facilitaria o nosso entendimento das necessidades dos clientes, revelando melhor seu perfil

25 Melhoraríamos nossa imagem junto aos clientes

Padronizaríamos processos ou produtos ofertados a clientes

Estabeleceríamos mecanismos que incentivariam

27 certos comportamentos desejáveis por parte dos clientes

Em um investimento que melhoraria a colaboração com parceiros e fornecedores

\section{RESPOSTAS}

Identificação dp projeto

(nome, sigla ou código)

marcar um " $X$ " na coluna adequada, representando a intensidade na escala de 1 a 5 , sendo: menor $=1$; maior $=5$

\section{$\begin{array}{llllll}1 & 2 & 3 & 4 & 5\end{array}$}

Infraestrutura

Resultados locais

Bem sucedido

marcar um " $X$ " na coluna adequada, representando a intensidade na escala de 1 a 5 , sendo: menor $=1$; maior $=5$

\section{Pouca redução nas dificuldades de clientes}

Não evitaria substituição

Não facilita entender o perfil do cliente

Não facilita entender o perfil do cliente

Não melhoraria nossa imagem

Não padronizaria processos/produtos

Pouco

Não aumentaria a colaboração

\section{$\begin{array}{lllll}1 & 2 & 3 & 4 & 5\end{array}$}

Muita redução nas dificuldades de clientes

Evitaria completamente a substituição

Facilitaria muito a identificação do produto

Facilita muito 0 entendimento do perfil do cliente

Melhoraria muito nossa imagem

Padroniza bastante os processos/ produtos

Muito

Aumentaria em muito a colaboração 
sucedidos e quais foram malsucedidos. De acordo com o MATIF, seria a pouca diferença entre o Valor Percebido da aplicação e o seu Valor Realizado o fator que classificaria, na prática, os casos entre bem-sucedidos e malsucedidos.

Assim, partindo de casos declarados pelas organizações como bem-sucedidos, temos duas possibilidades (Figura 5):

(a) Valor Potencial $\approx$ Valor Percebido $\approx$ Valor Realizado

(b) Valor Potencial $\gg$ V Valor Percebido $\approx$ Valor Realizado

Já para os investimentos tidos como malsucedidos, temos duas possibilidades:

(c) Valor Potencial $\approx$ Valor Percebido $\gg$ Valor Realizado

(d) Valor Potencial $\ll$ Valor Percebido $\gg$ Valor Realizado

As situações (a) e (b) são tidas como bem-sucedidas na aplicação de TI, mas não representam, necessariamente, a EFETIVIDADE do uso da tecnologia, porque no caso (b) a organização não tirou todo o proveito possível dessa aplicação.

Já o caso (c) representa uma situação em que a Gestão da TI não é efetuada de forma adequada ou reflete grande influência das barreiras de contingências.

Figura 4 - Etapas de condução da pesquisa
Os casos (b) e (d) correspondem àqueles em que 0 potencial de contribuição do MATIF é maior, visto que há grande desequilíbrio entre o Valor Potencial e o Valor Percebido.

Assim, para a execução desta pesquisa, procuramos tanto por casos incorporados que representassem aplicações bem-sucedidas de tecnologia quanto por casos que fossem considerados malsucedidos, atendendo às características de (b) e (d), de maneira que fosse permitida uma análise com três elementos, conforme Figura 6.

\section{Coleta de dados e validação}

Além das entrevistas, material adicional foi coletado por análise documental e observação direta, quando o pesquisador participou de reuniões de avaliação final sobre o sucesso dos projetos de TI. Dessas reuniões participaram não apenas os informantes, mas também um grupo ampliado, usualmente incluindo o principal executivo da área de tecnologia. A análise documental consistiu no levantamento de informações dos projetos de investimento - conhecidos como business-cases -, em particular procurando identificar os benefícios que os projetos objetivavam auferir no momento de sua proposição para aprovação

\begin{tabular}{|c|}
\hline $\begin{array}{c}\text { FASE I - APROXIMAÇÃO } \\
\text { (interface: FACILITADORES) }\end{array}$ \\
\hline Escolha dos casos \\
\hline $\begin{array}{c}\text { Abordagem aos facilitadores } \\
\text { (abertura de contato) }\end{array}$ \\
\hline $\begin{array}{c}\text { Encaminhamento do questionário } \\
\text { estruturado }\end{array}$ \\
\hline $\begin{array}{c}\text { Entrevista de identificação dos } \\
\text { informantes relevantes } \\
\text { (ESTRUTURA DA DECISÃO) }\end{array}$ \\
\hline
\end{tabular}


Especial atenção foi dada à coleta de dados, visando a isolar as eventuais falhas de percepção de valor dos executivos, especial mente aquelas advindas da recriação retrospectiva do entendimento sobre o valor percebido à época da tomada da decisão (MILES eHUBERMAN , 1994; KLEIN e MYERS, 1999).

Três modos de análise dos dados foram utilizados para interpretar o significado do conteúdo obtido: hermenêutica, narrativa e semiótica (DAVIS e outros, 1992) e permitir a triangulação das evidências encontradas. Essas técnicas foram particularmente úteis à medida que, em geral, entrevistados tendem a recriar o racional da decisão, usual mente produzido algum tempo antes de a entrevista ser conduzida, o que pode levar a expressarem interpretações favoráveis de seus próprios comportamentos passados ou do grupo interno à organização a que pertençam, especialmente quando os entrevistados estão diretamente envolvidos nas decisões ou implementações (AVISON e MYERS, 1995).

Nesta pesquisa, o uso da hermenêutica foi conduzido na tentativa de permitir o entendimento do significado dos textos ou narrativas dos entrevistados. Em uma organização, os diversos atores podem apresentar interpretações confusas, incompletas ou contraditórias a respeito dos assuntos a serem analisados. 0 objetivo do uso da hermenêutica consiste, então, em procurar construir o sentido do todo e o relacionamento dos seus el ementos. N esta pesquisa, os informantes estavam sujeitos a pressões de variadas origens, tais como a de comprovar que sua própria área tem relevância na organização, que as decisões tomadas foram adequadas, que sua participação foi consistente, bem como a de apresentar uma boa imagem da instituição ao pesquisador. Por isso, recriações ex-post do racional de tomadas de decisão coletivas tendem a se-

Figura 5 - Casos com aplicação de TI tida como mal ou bem-sucedida
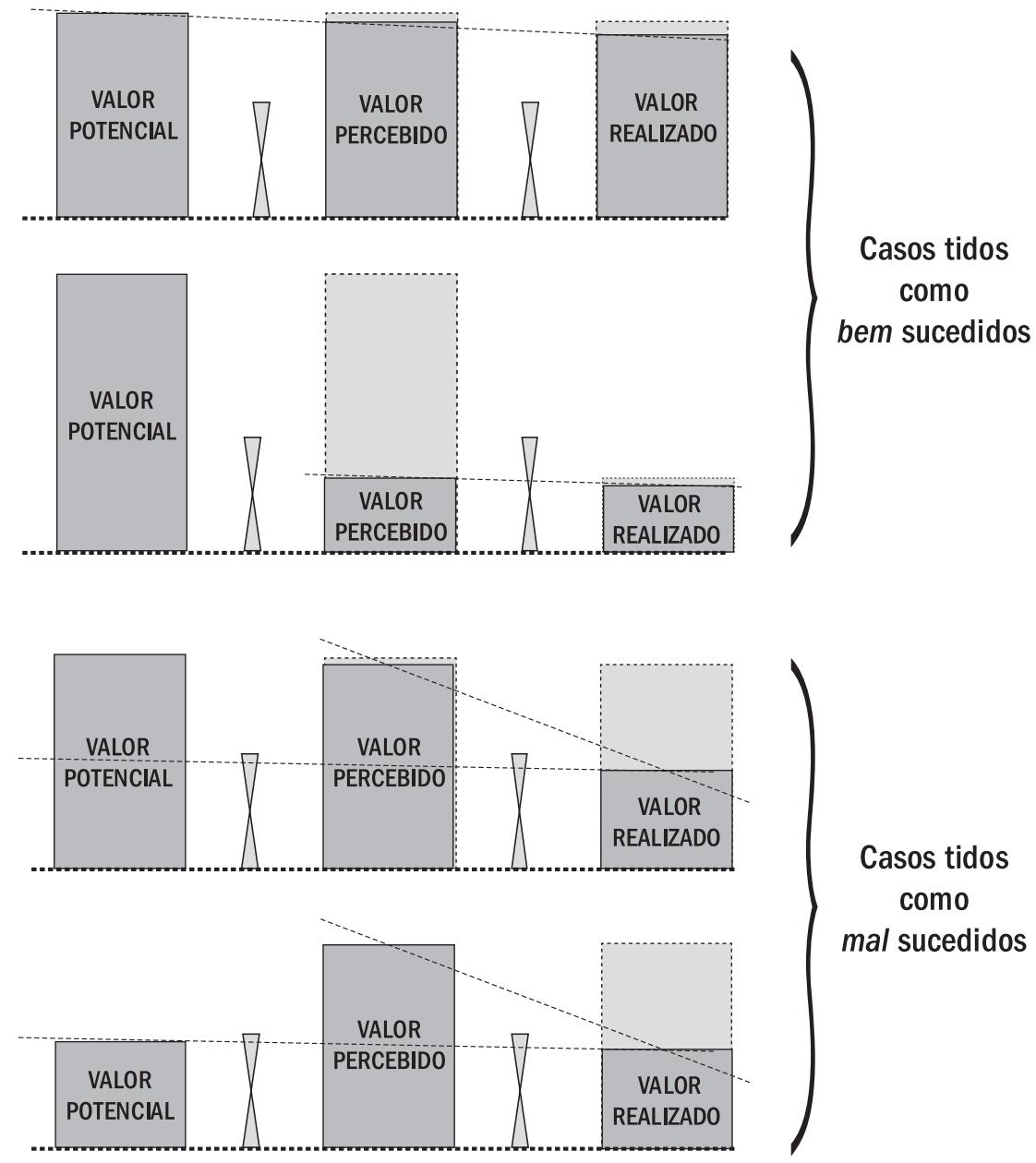
guir uma lógica que envolve uma miscelânea de aspectos políticos e técnicos. A hermenêutica ajuda a filtrar 0 significado da narrativa porque auxilia o pesquisador a procurar identificar e reconstruir conexões lógicas entre os el ementos das narrativas. N a prática, seu uso consistiu em procurar confirmação a cada argumento não objetivo ou isento de conexão com o tema da pesquisa em uma dinâmica que se aproxima de um interrogatório. Todo 0 procedimento foi gravado, transcrito e verificado posteriormente por meio de técnicas de categorização. A técnica de análise de narrativa trata de considerar a recriação de uma realidade que é, essencialmente, interpretada pelos informantes. Para essa recriação, o entrevistado utilizará metáfora, que é a aplicação de um nome, termo ou frase

Quadro 4 - Percepção de Sucesso/ Fracasso dos Projetos

\begin{tabular}{|c|c|c|c|c|}
\hline \multicolumn{2}{|c|}{ BANCO } & PROJETO & PERCEPÇÃO INICIAL & PERCEPÇÃO FINAL \\
\hline \multirow{3}{*}{ A } & 1 & Gerenciador de relacionamento & Muito efetivo & Fracasso \\
\hline & 2 & Correspondente bancário & Efetivo & Sucesso (em andamento) \\
\hline & 3 & Broker & Efetivo (médio) & Muito sucesso \\
\hline \multirow{4}{*}{ B } & 4 & Call center & Efetivo & Sucesso \\
\hline & 5 & Sistema de alocação de custos & Muito efetivo & Fracasso \\
\hline & 6 & Emissor de extrato & Efetivo & Fracasso \\
\hline & 7 & Comprovante de pagamento & Pouco efetivo & Muito sucesso \\
\hline C & 8 & Otimizador de entrega de numerário & Efetivo & Muito sucesso \\
\hline
\end{tabular}

Figura 6 - Critério de escolha dos projetos para análise de valor

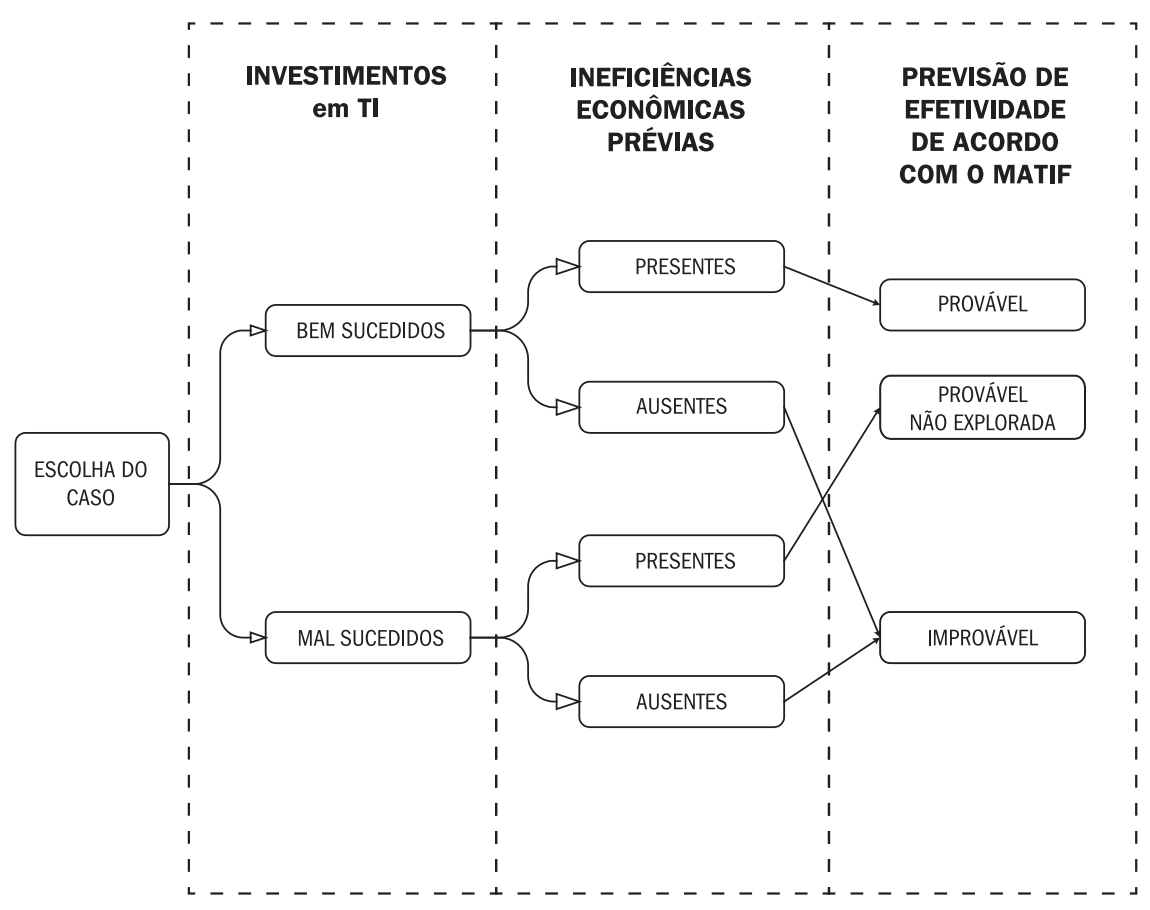


para designar um objeto ou ação em que não é diretamente aplicável. A análise dessas metáforas e das condições em que são empregadas pode revelar aspectos da narrativa que não são diretamente visíveis em um primeiro momento. A percepção desse aspecto exige muita disciplina verbal por parte do entrevistador, que deve não só registrar os aspectos observados, mas também instigar o entrevistado a confirmar ou graduar 0 aspecto que tenha acabado de revelar. Já a semiótica preocupa-secom a análise de significados de sinais esímbolos. A idéia básica é de que eles contêm significados incorporados, mas não revelados diretamente. Nesta pesquisa, os entrevistados utilizaram de forma intensa jargões presentes tanto na área de tecnol ogia de informação como na área de negócios e neologismos, em geral, oriundos das culturas organizacionais das instituições e da área de tecnologia da informação. Sinais como o de consentimento na tomada da palavra, graus de formalização da estrutura, rituais, como uso de assistentes para marcação das entrevistas e espera na ante-sala, ou ainda a ordem e a posição tomada junto à mesa de reuniões, todos eles ajudaram a revelar detalhes da estrutura de decisão que permitiram identificar quando algumas entrevistas deveriam ser conduzidas individualmente para que a autoridade formal da instituição não influísse demasiadamente na apresentação de detal hes pelos informantes. 0 pesquisador usou ainda 0 artifício da gravação das entrevistas que posteriormente foram codificadas, levando em conta o uso do jargão próprio de cada organização. Informações detal hadas sobre a condução dessas e outras técnicas podem ser consultadas em Miles e Huberman (1994), Spraley (1979) e Denzin e Lincoln (2003).

No Banco A, foram entrevistados o Vice-Presidente de Tecnologia, o Diretor de Tecnologia da Informação, o Superintendente Executivo de Soluções de Varejo, 0 Superintendente Executivo de Internet, o Superintendente Executivo de Soluções de Inteligência, o Superintendente Executivo de Serviços e Operações. Já no Banco B, foram entrevistados o Diretor Executivo de Tecnologia da Informação, o Superinten dente de Arquitetura, o Gerente de Investimento, enquanto, no Banco $C$, foram entrevistados o Vice Presidente de Operações, a Diretora Executiva deTecnologia da Informação, o Superintendente de Custos e Orçamentos. 0 período da pesquisa de campo foi de seis meses, de outubro de 2005 a março de 2006.

0 procedimento completo de condução da pesquisa é indicado na Figura 4.

Os resultados foram coletados sistematicamente, projeto a projeto, seguindo a seqüência indicada pelo protocolo de estudo. Para cada projeto, foram levantadas as impressões de todos os entrevistados sobre valor perce- bido, valor realizado e argumentos de benefícios que se geraria com a implementação de cada projeto para cada um dos atributos do M ATIF : utilidade, cooperação, complementaridade, gestão de risco. U ma breve descrição de cada projeto é apresentada no Quadro 5.

\section{ANÁLISE DOS RESULTADOS E DISCUSSÃO}

Os argumentos apresentados como justificativas prévias para cada projeto foram sistematicamente analisados, visando a caracterizar o valor potencial como resultado da combinação da possível contribuição do projeto em resolver os casos de ineficiências econômicas prévias em cada situação de negócio em que o projeto seria aplicado, considerando as dimensões utilidade, cooperação, complementaridade, gestão de risco do MATIF.

Assim, a fase de análise consistiu em verificar se haveria a possibilidade de enquadramento da justificativa dos projetos nas dimensões teóricas do M ATIF, considerandose a possibilidade de ocorrência de ineficiências econômicas prévias em cada situação em que um projeto seria aplicado e as respostas obtidas. Posteriormente, o valor potencial foi confrontado com as narrativas de valor percebido e realizado.

Por exemplo, para a dimensão de relacionamento com clientes, cujo atributo econômico principal é a geração de utilidade, procurou-se identificar se os casos apresentavam, à época da decisão do investimento, uma ou mais situações passíveis de representar ineficiência econômica, conforme previsto no construto. Assim, para a dimensão de clientes, cada projeto foi analisado sob a ótica da possibilidade de potencial de geração de valor pela aplicação da TI que resolvesse um ou mais dos seguintes problemas: altos custos impostos a clientes para a localização das soluções ou serviços adequados, baixos custos de substituição de produtos ou serviços do banco em relação à concorrência, altos custos de transação na entrega do produto ou prestação do serviço, dificuldade do banco em coordenar clientes (monitorar, controlar), baixa padronização, levando a deseconomias de escala, insuficiência de reputação que requeresse a entrega de garantias custosas, exposição do banco à possibilidade de clientes apresentarem moral hazard, exposição do banco a situações de seleção adversa de perfis inadequados de clientes. Um exemplo de narrativa e classificação dos resultados para a dimensão Clientes é ilustrado no Quadro 6.

0 mesmo procedimento foi executado para cada uma das dimensões e projetos. 0 resultado final das análises das cinco dimensões e oito projetos éilustrado no Quadro 
7. A análise dos dados, em especial a coluna de valor potencial ver sus val or percebido indica que apenas as expectativas originais dos projetos 2 e 4 deveriam ser mantidas, enquanto as expectativas dos demais seis projetos (total de oito) deveriam ser corrigidas. A correspondência entre os dados da coluna "correção da expectativa", cuja avaliação foi produzida utilizando-se o quadro conceitual da EEIH, com o conteúdo da coluna "percepção final" indica a validade da generalização convergente e discri- minante do construto para a explicação do fenômeno (EISENHARDT, 1989).

A análise das entrevistas e do material colhido permitiu identificar al guns importantes aspectos envolvidos na percepção do valor potencial dos projetos. São eles: (a) a estruturação do processo de decisão e (b) as habilidades individuais dos gestores para identificar ineficiências econômicas prévias na dinâmica dos negócios e mitigá-las pela aplicação da TI.

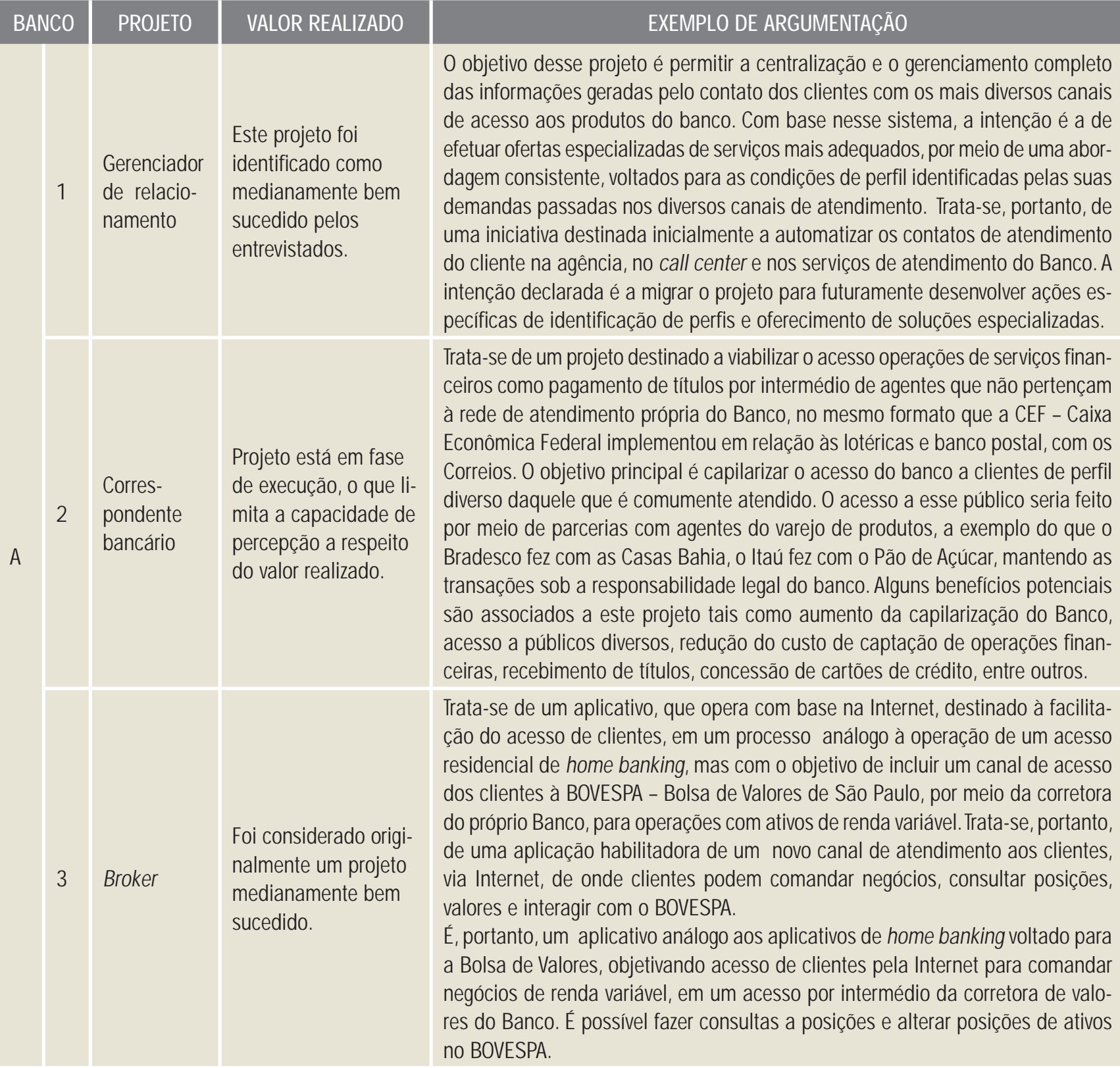




\begin{tabular}{|c|c|c|c|c|}
\hline \multirow{4}{*}{ B } & 4 & Call center & $\begin{array}{l}\text { No momento da pes- } \\
\text { quisa, era um projeto } \\
\text { de escopo conside- } \\
\text { rado grande, com } \\
\text { etapas que ainda vão } \\
\text { ocorrer. } \\
\text { Era considerado bem } \\
\text { sucedido }\end{array}$ & $\begin{array}{l}\text { Trata-se de um projeto destinado a concentrar as operações de atendimento a } \\
\text { cliente que são suportadas por sistema. A situação que o projeto busca resolver } \\
\text { consiste de garantir que todas as atividades com o tipo de atendimento por call } \\
\text { center, tais como operações de financeira, seguros, suporte a clientes, SAC, entre } \\
\text { outras, sejam consolidadas em um ambiente único, físico e lógico. }\end{array}$ \\
\hline & 5 & $\begin{array}{l}\text { Sistema de } \\
\text { alocação de } \\
\text { custos }\end{array}$ & $\begin{array}{l}\text { Projeto claramen- } \\
\text { te identificado com } \\
\text { malsucedido. Nas } \\
\text { palavras do entrevis- } \\
\text { tado "... tudo que se } \\
\text { desenvolveu naque- } \\
\text { la época foi jogado } \\
\text { fora". }\end{array}$ & $\begin{array}{l}\text { Trata-se de um projeto destinado a permitir uma visão de alocação de custos de } \\
\text { TI para as áreas de negócio. Desenvolvido com o suporte de uma grande empresa } \\
\text { internacional fornecedora de sistemas de gestão empresarial e de uma grande } \\
\text { empresa de consultoria, objetivava a implantação do ABC - Activity Based Cost } \\
\text { para apropriar os custos de desenvolvimento e processos de Tl aos variados pro- } \\
\text { dutos das áreas de negócios. O objetivo principal deste projeto foi permitir uma } \\
\text { melhor alocação dos custos de cada solução, de modo a que o Banco tivesse a } \\
\text { visão clara das soluções que são rentáveis. } 0 \text { escopo do projeto envolveu apenas } \\
\text { os aspectos de custos e orçamentação, já que os aspectos contábeis e fiscais } \\
\text { estão sendo atendidos por outra aplicação. }\end{array}$ \\
\hline & 6 & $\begin{array}{l}\text { Emissor de } \\
\text { extrato }\end{array}$ & $\begin{array}{l}\text { Embora já termina- } \\
\text { do e com o potencial } \\
\text { de economia direta } \\
\text { de alguns milhões de } \\
\text { reais ao ano, o pro- } \\
\text { jeto foi considerado } \\
\text { malsucedido. }\end{array}$ & $\begin{array}{l}\text { Trata-se de um projeto de alteração do formato de envio de extratos para os } \\
\text { clientes. O processo existente de envio de extratos é feito pelo meio tradicional } \\
\text { de envelopagem convencional, com janela de destinatário. } 0 \text { procedimento de- } \\
\text { senvolvido executa a impressão dos extratos pelo sistema chacon, que consiste } \\
\text { de uma única folha convenientemente dobrada que dispensa o uso de envelo- } \\
\text { pagem, sendo a impressão feita em preto e branco, diferentemente do conven- } \\
\text { cional, que é colorido. }\end{array}$ \\
\hline & 7 & $\begin{array}{l}\text { Compro- } \\
\text { vante de } \\
\text { pagamento }\end{array}$ & $\begin{array}{l}\text { Projeto foi conside- } \\
\text { rado muito bem- } \\
\text { sucedido }\end{array}$ & $\begin{array}{l}\text { Trata-se de um projeto destinado a tornar disponíveis cópias de cheques dos } \\
\text { clientes que foram processados, em substituição aos antigos processos de recu- } \\
\text { peração por microfilmagem. Isso se torna possível porque, no processamento, já } \\
\text { é criada a imagem do cheque e que fica disponível em um Banco de dados. }\end{array}$ \\
\hline C & 8 & $\begin{array}{l}\text { Otimiza- } \\
\text { dor de } \\
\text { entrega de } \\
\text { numerário }\end{array}$ & $\begin{array}{l}\text { Projeto muito bem- } \\
\text { sucedido, conforme a } \\
\text { narrativa de um dos } \\
\text { entrevistados: "... ao } \\
\text { final, as economias } \\
\text { foram muito supe- } \\
\text { riores ao projetado } \\
\text { inicialmente...". }\end{array}$ & $\begin{array}{l}\text { Trata-se de um sistema implantado para otimizar o atendimento à demanda de } \\
\text { numerário das agências, reduzindo os custos de logística na operação e man- } \\
\text { tendo os riscos sob níveis adequados. A aplicação substituiu os processos an- } \\
\text { teriores que consistiam de atender diariamente aos requisitos das agências em } \\
\text { relação ao volume de numerário e recolher os excedentes ao final do dia. Isso } \\
\text { significava que cada agência tinha obrigatoriamente, pelo menos, dois atendi- } \\
\text { mentos diários. Destina-se a otimizar a atividade de planejar a necessidade de } \\
\text { numerário para as agências que, no procedimento anterior à implementação do } \\
\text { projeto, consistia de requisitar numerário todos os dias e devolver o excedente } \\
\text { em uma operação de transporte que tinha duas visitas da transportadora por } \\
\text { agência, por dia. } 0 \text { recurso vai, então, para uma central da transportadora que } \\
\text { confere e controla o numerário. }\end{array}$ \\
\hline
\end{tabular}

(a) Estruturação do processo de decisão: a estrutura de decisão das organizações tem papel preponderantena facilitação dessa percepção. As ineficiências podem surgir entre relacionamentos com diversos agentes econômicos, o que usual mente ocorre nos limites de decisão e percepção de áreas funcionalmente dife- rentes da organização que estão sob responsabilidade de diferentes gestores. Por exemplo, uma decisão de investimentos que tenha o objetivo de gerar valor adicional ao cliente deve envolver, além deste, outros múltiplos aspectos, como, por exemplo, o risco (tecnológico) da solução, o impacto no risco do negócio 
de se implementar o projeto, as complementaridades com recursos internos e externos e as economias e deseconomias de escala e escopo, em um alinhamento geral da organização, difícil de ser capturado se a estrutura da decisão não for orientada para o refinamento da percepção desses aspectos, usualmente localizados, mas que se conectam e alinham como um todo, conforme ilustrado na Figura 2.

(b) Habilidades individuais dos gestores: a habilidade de perceber previamente as ineficiências econômicas que podem vir a ser resolvidas pela implementação dos projetos que estão sob análise é essencial para uma adequada tomada de decisão a respeito desses projetos. A ocorrência de situações em que os gestores são surpreendidos pel o val or gerado por projetos, mesmo quando as organizações são proficientes nas melhores técnicas de análise, demonstra que tais técnicas são incompletas para a produção de uma decisão efetiva. Após a introdução do MATIF como guia de análise dos elementos que sustentariam a decisão sobre 0 projeto, os gestores foram capazes de identificar separadamente os componentes envolvidos na geração de valor para o negócio. Assim, concluímos que nem todos os gestores têm, em vista dos instrumentais disponíveis, os meios para identificar as situações de ineficiência econômica. Nosso estudo revelou que a introdução dos elementos do M ATIF contribui para melhor estruturação da decisão de investimentos.

\section{CONCLUSÕES}

Considerando que a TI representa um recurso estratégico e caro, as organizações têm procurado encontrar maneiras de mel hor gerir esse recurso. Várias organizações têm reconhecido que uma parcel a significativa dos benefícios obtidos pela sua utilização é intangível e, por isso, de difícil mensuração. $\mathrm{N}$ a tentativa de contornar essa dificul-

Quadro 6 - Avaliação e exemplo de evidências para a dimensão utilidade

\begin{tabular}{|c|c|c|c|c|}
\hline \multicolumn{2}{|c|}{ BANCO } & PROJETO & AVALIAÇÃO & EXEMPLO DE ARGUMENTAÇÃO \\
\hline \multirow{3}{*}{ A } & 1 & $\begin{array}{l}\text { Gerenciador de } \\
\text { relacionamento }\end{array}$ & (t) potencial & $\begin{array}{l}\text { "[...] inicialmente se tinha uma expectativa que essa ferramenta atenderia to- } \\
\text { dos os segmentos do Banco, mas não foi o que aconteceu [...]" }\end{array}$ \\
\hline & 2 & $\begin{array}{l}\text { Correspondente } \\
\text { bancário }\end{array}$ & muito intensa & $\begin{array}{l}\text { "[...] sob o ponto de vista com cliente, há redução do custo de transação. } \\
\text { Assim o cliente tem uma oferta de produtos e serviços bancários em canais } \\
\text { diferenciados que exploram a capilarização do acesso, que de outra forma } \\
\text { não poderia ter acesso a serviços bancários adequados à sua capacidade } \\
\text { de pagamento [...]" }\end{array}$ \\
\hline & 3 & Broker & muito intensa & $\begin{array}{l}\text { "[...] a corretora provê um serviço que, de outra forma, deve ser concluído por } \\
\text { meio telefônico, por meio de um operador ou trader. Pelo Broker, o cliente lo- } \\
\text { caliza facilmente a alternativa de ativos que deseja. Muitos clientes, por não } \\
\text { necessitarem de aconselhamentos, vêem a intermediação do trader como uma } \\
\text { dificuldade adicional, não necessariamente como uma facilitação [...]" }\end{array}$ \\
\hline \multirow{4}{*}{ B } & 4 & Call center & nenhum & Operação já existente. Tratou-se de otimização interna. \\
\hline & 5 & $\begin{array}{l}\text { Sistema de alocação } \\
\text { de custos }\end{array}$ & (t) potencial & $\begin{array}{l}\text { Surgiria, no futuro, se a alocação levasse a uma redução dos custos de } \\
\text { transação. }\end{array}$ \\
\hline & 6 & Emissor de extrato & $\begin{array}{l}\text { (- -) redução de } \\
\text { utilidade }\end{array}$ & $\begin{array}{l}\text { "[...] o projeto eliminou um canal de comunicação com o cliente, que passou } \\
\text { a perceber como oneroso e difícil o acesso à informação sobre os produtos } \\
\text { do banco [...]" }\end{array}$ \\
\hline & 7 & $\begin{array}{l}\text { Comprovante de } \\
\text { pagamento }\end{array}$ & $\begin{array}{l}\text { presente, } \\
\text { oculta }\end{array}$ & $\begin{array}{l}\text { "[...] serve a clientes que desejam atender a requisitos judiciais de compro- } \\
\text { vação de pagamentos. Esses clientes, até então, precisavam se submeter a } \\
\text { procedimentos burocráticos de requisição, tempo de espera e, eventualmente, } \\
\text { não-atendimento no prazo desejado". }\end{array}$ \\
\hline C & 8 & $\begin{array}{l}\text { Otimizador de entrega } \\
\text { de numerário }\end{array}$ & nenhum & $\begin{array}{l}\text { Tratou-se de otimização da operação de distribuição de numerário, sem refle- } \\
\text { xos perceptíveis ao cliente. }\end{array}$ \\
\hline
\end{tabular}


dade de objetivação dos ben efícios, etapa fundamental na adequada avaliação dos projetos de investimento, al gumas organizações adotam diversas técnicas de avaliação do projeto e de estruturação do processo de decisão.

As organizações têm a tendência de atribuir aos gestores das áreas de negócio a responsabilidade pela correta percepção de valor que a TI terá para o negócio, instituindo a gestão por orçamentos em base zero, em que os custos são centralizados, rateados e apropriados, com base em alguns critérios, às áreas de negócio que têm a responsabilidade de apresentar resultados. Entretanto, nem sempre os gestores das áreas de negócio e gestores das áreas de TI são completamente conhecedores dos variados aspectos envolvidos nas decisões de investimento, por mais qualificados que possam ser os métodos empregados atualmente. M esmo as organizações proficientes na compreensão do valor da utilização da TI nos negócios, e na sua gestão, apresentam casos de surpreendentes su- cessos ou insucessos.

As teorias atual mente aplicadas pelas organizações não são suficientemente eficazes para revelar corretamente 0 valor potencial dos investimentos. A EEIH apresenta contribuição rel evante para a formação da base conceitual que permite explicar os casos até então não explicados, ao facilitar uma melhor percepção da potencialidade de valor dos projetos de TI e permitir melhor decisão de investimento.

Vários trabal hos têm tratado da orientação a respeito da aplicação da TI pelas organizações. Entretanto, esses trabalhos têm focado isoladamente aspectos estratégicos, análise dos investimentos e princípios econômicos. A contribuição deste trabalho consiste em detal har como a EEIH, por meio da aplicação do modelo MATIF, pode contribuir para a melhoria dessa percepção e conseqüente aumento da efetividade dos investimentos em TI pelas organizações, tendo como base um modelo integrado da

Quadro 7 - Resultados da Avaliação dos Projetos Utilizando o MATIF

\begin{tabular}{|c|c|c|c|c|c|c|c|}
\hline \multicolumn{2}{|c|}{ BANCO } & PROJETO & $\begin{array}{c}\text { ATRIBUTO E } \\
\text { INTENSIDADE (+ OU -) }\end{array}$ & $\begin{array}{l}\text { POT } \\
\text { PER }\end{array}$ & $\begin{array}{l}\text { IAL X } \\
\text { IDO }\end{array}$ & $\begin{array}{l}\text { CORREÇÃO DA } \\
\text { EXPECTATIVA }\end{array}$ & $\begin{array}{l}\text { ATRIBUTOO } \\
\text { DO NEGÓCIO }\end{array}$ \\
\hline \multirow{3}{*}{ A } & 1 & $\begin{array}{l}\text { Gerenciador de } \\
\text { relacionamento }\end{array}$ & $\begin{array}{c}\text { utilidade } \\
(+, \text { potencial })\end{array}$ & 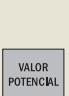 & 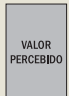 & $\begin{array}{l}\text { Reduzir } \\
\text { Muito }\end{array}$ & Valor do Cliente \\
\hline & 2 & $\begin{array}{l}\text { Correspondente } \\
\text { bancário }\end{array}$ & $\begin{array}{c}\text { cooperação }(++) \\
\text { utilidade }(++) \\
\text { gestão de risco (-) }\end{array}$ & 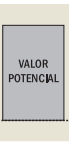 & 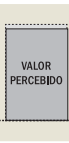 & manter & $\begin{array}{l}\text { Participação de } \\
\text { Mercado }\end{array}$ \\
\hline & 3 & Broker & $\begin{array}{c}\text { utilidade (t+) } \\
\text { complementaridade (t+) }\end{array}$ & 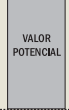 & & $\begin{array}{l}\text { Elevar } \\
\text { Muito }\end{array}$ & Utilização de Ativos \\
\hline \multirow{4}{*}{ B } & 4 & Call center & $\begin{array}{l}\text { complementaridade }(t) \\
\text { cooperação }(t)\end{array}$ & 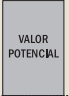 & 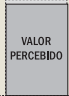 & manter & Utilização de Ativos \\
\hline & 5 & $\begin{array}{l}\text { Sistema de } \\
\text { alocação de } \\
\text { custos }\end{array}$ & $\begin{array}{l}\text { complementaridade (- -) } \\
\text { gestão de risco (- -) } \\
\text { utilidade (+, potencial) }\end{array}$ & 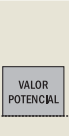 & $\begin{array}{l}\text { vaA } \\
\text { PePC }\end{array}$ & $\begin{array}{l}\text { Reduzir } \\
\text { Muito }\end{array}$ & $\begin{array}{l}\text { Estrutura de custos } \\
\text { (potencial) }\end{array}$ \\
\hline & 6 & Emissor de extrato & utilidade (- -) & $\begin{array}{l}\text { valar } \\
\text { portcon }\end{array}$ & 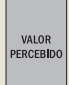 & $\begin{array}{l}\text { Reduzir } \\
\text { Muito }\end{array}$ & Estrutura de custos \\
\hline & 7 & $\begin{array}{l}\text { Comprovante de } \\
\text { pagamento }\end{array}$ & $\begin{array}{c}\text { utilidade }(++) \\
\text { complementaridade }(+)\end{array}$ & 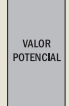 & valor & $\begin{array}{l}\text { Elevar } \\
\text { Muito }\end{array}$ & Valor do Cliente \\
\hline C & 8 & $\begin{array}{l}\text { Otimizador de } \\
\text { numerário }\end{array}$ & cooperação (t) & 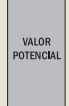 & 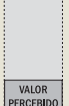 & Elevar & Utilização de Ativos \\
\hline
\end{tabular}


firma e de seus relacionamentos com os diversos agentes econômicos.

N ossa anál ise indicou que a efetividade al cançada pelo uso da TI está relacionada com a habilidade dos gestores de identificarem ineficiências econômicas prévias na dinâmica dos negócios e mitigá-las pela aplicação da TI. Esta é, entretanto, uma habilidade ainda não estruturada nem completamente utilizada pelas organizações no processo de decisão de investimentos.

Embora indiquemos que as conclusões deste trabalho podem não ser diretamente generalizáveis para outros contextos diferentes dos definidos por esta pesquisa, sugerimos que futuros trabalhos possam explorar e aprofundar a aplicação dos conceitos da EEIH nas análises de investimento em TI pelas organizações. Quanto à prática gerencial, melhorias na maneira pela qual uma organização específica avalia seus investimentos em TI poderão levar ao aumento de seu desempenho em função da efetividade com que aplica seus recursos.

0 presente artigo baseia-se em pesquisa financiada pela Escola de Administração de Empresas de São Paulo, da Fundação Getulio Vargas.

\section{REFERÊNCIAS}

ALBERTIN, A. L. Valor estratégico dos projetos de tecnologia de informação. RAE-revista de administração de empresas, v. 41, n. 3, p. 42-50, jul./set. 2001.

AVISON, D. E; MYERS, M. D. Information systems and anthropology: an anthropological perspective on IT and organizational culture. Information Technology \& People, v. 8, n. 3, p. 43-57, 1995.

BACEN - BANCO CENTRAL DO BRASIL. Evolution of accountablevalues of financial institutions in Brazil. Brasilia, 2006. Disponível em: http://www. bcb.gov.br/fis/TOP50/port/Top502005030P.asp. Acesso em 13.06.2006.

BAILEY, J. P; BAKOS, J. Y. An exploratory study of the emerging role of electronic intermediaries. International Journal of Electronic Commerce, $v$. 1, n. 3, p. 7-21, 1997.

BARUA, A; KRIEBEL, C. H; MUKHOPADHYAY, T. Information technologies and business value: an analytic and empirical investigation. Information Systems Research, v. 6, n. 1, p. 3-24, 1995.

BASSELLIER, G; BENBASAT, I; REICH, B. H. The influence of business managers' IT competence on championing. Information Systems Research, v. 14, n. 4, p. 317-337, 2003.

BENAROCH, M. Option-based management of technology investment risk. IEEE Transactions on Engineering M anagement, v. 48, n. 4, p. 428-445, 2001.
BENAROCH, M; KAUFFMAN, R. A case for using real options pricing analysis to evaluate information technology project investments. Information Systems Research, v. 10, n. 1, p. 70-87, 1999.

BENBASAT, I; GOLDSTEIN, D. K; MEAD, M. The case research strategy in studies of information systems. MIS Quarterly, v. 5, n. 4, p. 369-386, 1987.

BODIE, Z; KANE, A; MARCUS, A. J. Investments. 4th ed. Irwin/McGrawHill, 1999.

BRYNJOLFSSON, E. The productivity paradox of information technology. Communications of the ACM , v. 35, n. 12, p. 66-78, 1993.

BRYNJOLFSSON, E; HITT, L. M. Productivity, business profitability and consumer surplus: three different measures of information technology value. MIS Quarterly, 1996.

BRYNJOLFSSON, E; HITT, L. M. Computing productivity: firm level evidence. Review of Economics \& Statistics, v. 85, n. 4, p. 793-809, 2003.

CASSON, M. C. Why are firms hierarchical? Journal of Economics of Business, v. 1, n. 1, p. 47-77, 1994.

CHAN DLER, A. D. J. Sale and scope: the dynamics of industrial capitalism. London: Harvard University Press, 1990.

CHANDLER, A. D. J. Strategy and structure: chapters in the history of the industrial enterprise. In: FOSS, N. J. Resourses Firms and Strategies. N ew York: Oxford University Press, 1997. p. 40-51.

CLEM ONS, E. K; HITT, L. M. Poaching and the misappropriation of information: transaction risks of information exchange. Journal of $M$ anagement Information Systems, v. 21, n. 2, p. 87-108, 2004.

CLEMONS, E; ROW, M. C. I. Information technology and industrial cooperation: The changing economics of coordination and ownership. Journal of Management Information Systems, v. 9, n. 2, p. 9-29, 1992.

DAVERN, M. J; KAUFFMAN, R. J. Discovering potential and realizing value from information technology investments. Journal of Management Information Systems, v. 16, n. 4, p. 121-144, 2000.

DAVIS, G. B. et al. Diagnosis of an information system failure: a framework and interpretive process. Information \& M anagement, v. 23, n. 5, p. 293-319, 1992.

DENZIN, N. K; LINCOLN, Y. S. Collecting and interpreting qualitative materials. London: Sage, 2003.

EISEN HARDT, K. M. Building theories from case study research. Academy of Management Review, v. 14, n. 4, p. 532-550, 1989.

EVANS, P. B; WURSTER, T. S. Blown to bits: how the economics of information transforms strategy. Boston, Massachusetts: Harvard Business School Press, 2000.

FEBRABAN, F. D. B. B. Asset ranking of brazilian banks. 2006. Disponível em: http://www.febraban.org.br/Arquivo/Servicos/Dadosdosetor/2006/ item13.asp. Acesso em 13.06.2006. 
GARDNER, C. The valuation of information technology: a guide for strategy, development, valuation, and financial planning. New York: John Wiley, 2000.

HUNT, S. D. Evolutionary economics, endogenous growth models, and resource-advantage theory. Eastern Economic Journal, v. 23, n. 4, 1997.

KLEIN, H. K; MYERS, M. D. A set of principles for conducting and evaluating interpretive field studies in information systems. MIS Quarterly, v. 23, n. 1, p. 67-93, Mar. 1999.

KOHLI, R; DEVARAJ, S. M easuring information technology payoff: a metaanalysis of structural variables in firm-level empirical research. Information Systems Research, v. 14, n. 2, p. 127-146, 2003.

MAYER, K. J; SALOMON, R. M. Capabilities, contractual hazards, and governance: integrating resource-based and transaction cost perspectives. A cademy of Management Journal, v. 49, n. 5, p. 942-960, 2006.

MEIRELLES, F. S. Administração de Recursos de Informática. 17. ed. Pesquisa Anual. São Paulo: Centro de Tecnologia da Informação Aplicada - CIA, FGV-EAESP, 2006.

MELVILLE, N; KRAEMER, K; GURBAXANI, V. Review: IT and organizational performance: an integrative model of it business value. M IS Q uarterly, v. 28, n. 2, p. 283-323, 2004.

MILES, M. B; HUBERMAN, A. M. Qualitative data analysis: an expanded sourcebook. 2. ed. London: Sage, 1994.

MILGROM, P; ROBERTS, J. Economics, organization and management. Upper Side River NJ: Prentice Hall, 1992.

OLIVEIRA, M; MAÇADA, A. C. G; GOLDONI, V. Análise da aplicação do método estudo de caso na área de sistemas de informação. In: ENCONTRO NACIONAL DA ASSOCIAÇÃO NACIONAL DOS PROGRAMAS DE PÓS-GRADUAÇÃO EM ADMINISTRAÇÃO, 30, 2006, Salvador. Anais. Salvador: ANPAD, 2006

ORLIKOW SKI, W. J. Knowing in practice: enacting a collective capability in distributed organizing. Organization Science, v. 13, n. 3, p. 249-274, 2002.

PENROSE, E. The theory of the growth of the firm. In: FOSS, N. J. Resourses, firms and strategies N ew York: Oxford University Press, 1997. p. 13.

PINDYCK, R. S; RUBINFELD, D. L. Microeconomia. 6. ed. São Paulo: Prentice Hall, 2006.

PORTER, M. E. Strategy and the internet. Harvard Business Review, v. 79, n. 3, p. 61-79, 2001.

POWELL, T. C; MICALLEF, A. D. Information technology as competitive advantage: the role of human, business and technology resources. Strategic Management Journal, v. 18, n. 5, p. 375-406, 1997.

PRAHALAD, C. K; HAMEL, G. The core competence of the corporation. Harvard Business Review, p. 79-92, May/June 1990.

REICH, B. H; BENBASAT, I. Factors that influence the social dimension of alignment between business and information technology objectives. MIS Quarterly, v. 24, n. 1, p. 81-112, 2000.
SANTHANAM, R; HARTONO, E. Issues in linking information technology capability to firm performance. MIS Q uarterly, v. 27, n. 1, p. 125-153, Mar. 2003.

SCHNIEDERJANS, M. J; HAMAKER, J. L; SCHNIEDERJANS, A. M. Information technology investment: decision-making methodology. N ew Jersey: World Scientific, 2004.

SHAPIRO, C; KATZ, M. L. Technology adoption in the presence of network externalities. Journal of Political Economy, v. 94, n. 4, p. 822-842, 1986.

SIMON, H. A. Rationality as process and as product of thought. The American Economic Review, v. 68, n. 2, p. 1-17, 1978.

SPRADLEY, J. P. The Ethnographic Interview. Belmont: Wadsworth-Thomson Learning, 1979.

TALLON, P. P; KRAEMER, K. L; GURBAXANI, V. Executive's perceptions of business values of information technology: a process-oriented aproach. Journal of Management Information Systems, v. 16, n. 4, p. 145-174, 2000 .

TEECE, D. J. Profiting from technological innovation: implications for integration, collaboration, licensing and public policy. In: TEECE, D. J. The competitive challenge. N ew York: Harper \& Row, 1987.

TEECE, D. J. Competition, cooperation, and innovation: organizational arrangements for regimes of rapid technological progress. Journal of Economic Behavior and Organizations, v. 18, n. 1, p. 1-26, 1992.

VARIAN, H. R. Intermediate microeconomics. 5. ed. New York: W.W. Norton, 1999.

VARIAN, H. R; SHAPIRO, C. Information rules: a strategic guide to the network economy. Boston: Harvard Business School Press, 1999.

VENKATRAMAN, N; HENDERSON, J. Real strategies for virtual organizing. Sloan Management Review, v. 40, n. 1, 1998.

WADE, M; HULLAND, J. Review: resource-based view of is research. MIS Quarterly, v. 28, n. 1, p. 107-143, 2004.

WEINTRAUB, E. R. How economics became a mathematical science. Duke University Press, 2002.

WILLIAMSON, O. E. Markets and hierarchies. New York: Free Press, 1975.

WILLIAMSO N, O. E. Transaction cost economics: the governance of contractual relations. Journal of Law and Economics, v. 22, n. 2, p. 233-262, 1979.

WILLIAMSON, O. E. Economic organization: firms, markets and policy control. New York: N ew York University Press, 1986.

WILLIAMSON, O. E. The mechanisms of governance. Oxford: Oxford University Press, 1996.

YIN, R. K. Case study research: design and methods. 3. ed. Newbury Park: Sage, 2002. 